\title{
Multiple Criteria Decision Analysis in Health Technology Assessment for Drugs: Just Another Illusion?
}

\author{
Livio Garattini ${ }^{1}$ - Anna Padula ${ }^{1}$
}

Published online: 18 August 2017

(c) Springer International Publishing AG 2017

Multiple criteria decision analysis (MCDA) is a branch of operational research and management science aimed at developing decision support tools for addressing complex problems involving high uncertainty, conflicting objectives, various forms of data and information, and heterogeneous interests and perspectives [1].

The basic idea of MCDA methods is to assess actions according to both quantitative and qualitative criteria that include all the main key points of a decision-making process, in order to buttress the exercise of judgment [2]. Therefore, MCDA can be considered a broad 'umbrella concept' [3], comprising various methods analyzing both objective and subjective measures to back the decisionmaking process and formally improve its transparency and consistency.

Since its inception in the 1970s [4], the use of MCDA has rapidly spread because of its potential for making the decision process more explicit and exhaustive [5]. MCDA methods have been successfully applied to help with appraisal projects in various fields where impacts cannot be readily quantified by monetary values, from engineering [6] to energy management [7], environmental sciences [8], and geographical information systems [9].

Livio Garattini and Anna Padula contributed equally.

Livio Garattini

livio.garattini@marionegri.it

1 IRCCS Institute for Pharmacological Research "Mario Negri”, 24020 Ranica, Italy
Recently, MCDA has been increasingly promoted as a potential tool to be extended to healthcare decision-making $[10,11]$. In fact, a major concern raised in the evaluation of public health interventions is that their requirements are not fully captured by present standard criteria [12]; thus, processes like MCDA, which systematically and explicitly address all key factors, looking at the options from multiple perspectives, seem attractive. The application of MCDA has been envisaged by various healthcare organizations and agencies to efficiently back different types of healthcare decisions [5, 13].

For pharmaceuticals, the European Medicines Agency (EMA) started developing and testing MCDA methods for use in regulatory decisions for the benefit-risk assessment of a medicinal product and post-approval monitoring of its benefit-risk balance [14, 15]. More recently, the German Institute for Quality and Efficiency in Health Care (IQWiG) conducted a methodological study to assess MCDA as a patient-preference elicitation tool for health technology assessment (HTA) [16], followed by two pilot projects in depression and hepatitis C [17, 18]. Subsequently, the UK National Institute for Health and Care Excellence (NICE) suggested that MCDA could be a tool to support cost-consequences analyses for more exhaustive HTAs [19].

Here we focus on the potential contribution of MCDA in HTA for pharmaceutical pricing and reimbursement (P\&R) in the EU. After a brief description of MCDA methods, we summarize the main features of HTA and discuss whether the two 'umbrella concepts' together might contribute to improving pharmaceutical $\mathrm{P} \& \mathrm{R}$ decisions. 


\section{Multiple Criteria Decision Analysis (MCDA) Methods}

All MCDA methods have a common basic structure, which can be described as follows [20]: (1) define the decision context by establishing the aim and identifying stakeholders and decision makers; (2) draw up a list of alternative options to be examined; (3) define the decisional criteria by identifying the factors that influence the choice of one alternative over another; (4) assess the performance of the alternatives selected by examining the consequences of each option and ranking the criteria from high- to low-level objectives $^{1}$; (5) rate the performance of each option and assess the value of each criterion; (6) weight all the decisional criteria to express their relative importance in the assessment; (7) combine scores and weights to obtain an overall score for ranking the alternatives; (8) conduct a sensitivity analysis to deal with uncertainty in results.

MCDA methods can be broadly classified in two categories: multi-objective decision making (MODM) and multi-attribute decision making (MADM) [21]. The former are adopted to tackle problems that have an infinite or a large number of choices, the best of which should optimize the decision makers' objectives and preferences-for example, the choice of energy volume obtained from renewable sources (infinite alternatives) to be used, so as to minimize environmental impact and maximize energetic income (objectives). MADM can be applied to problems that present a finite number of alternatives, aimed at reaching a single objective by analyzing a defined set of criteria-for example, the choice of a car out of a selected range of different types (alternatives), on the basis of cost, comfort, and fuel consumption (criteria). MADM methods too can be grouped in two approaches [22]. In value measurement models a preference score is assigned to one option over another, while in outranking models a pairwise comparison of alternatives is conducted on each criterion and the contribution of each one is measured for ranking alternatives.

In general, a challenge for MCDA users is that there are many methods available [5], which differ not only in how they are applied but also in their fundamental theories and underlying beliefs [23]. The definition of MCDA encompasses a wide range of different approaches for facilitating

\footnotetext{
1 The most important trade-off between the objectives appears at the top of the hierarchy. For instance, this is mainly between costs and benefits for HTAs. Thus, the very top objective is the overall result, taking both costs and benefits into account. The next level down should consider costs as one objective and benefits as another. Costs can then be broken down into monetary and non-monetary costs, or short- and long-term costs, and so on. The same applies to benefits. This hierarchical representation is often referred to as a 'value tree'.
}

replicability and transparency when decisions are based on more than one criterion.

\section{Health Technology Assessment}

HTA is now widely used for pharmaceutical P\&R in the EU healthcare systems. Born in North America in the mid1970s [24], HTA should bridge the gap between clinical evidence and healthcare policy decisions [25]. According to the International Network of Agencies of HTA, "HTA is a multidisciplinary field of policy analysis, which studies the medical, social, ethical and economic implications of development, diffusion, and use of health technology". Therefore, HTA can be considered a 'melting pot' of different disciplines dealing with various and somewhat contrasting needs [25]. Experts are mainly epidemiologists, health economists, physicians, and pharmacists, brought together to assess health technologies from the policy makers' viewpoint. The expected outcomes are recommendations bridging evidence-based medicine, economic evaluation, legal and ethical implications, professional experience, and patient preferences.

In practice, after almost half a century since its inception, the main HTA 'ingredients' are still clinical efficacy and healthcare costs to conduct full economic evaluations (EEs) [26] (mainly cost-effectiveness analyses), while other disciplines like ethics are seldom covered [27]. However, even as a part of HTA, EE itself implies a multidisciplinary approach, at least requiring clinical, epidemiological, economic, and administrative inputs [28].

\section{Commentary}

According to a flourishing literature [5, 10-13, 22, 23, 29-32], MCDA methods can improve the HTA decision-making contribution to pharmaceutical policy. All these articles share the conclusion that MCDA methods can strengthen P\&R decisions based on HTAs, since the latter involve multiple factors that may be conflicting and a variety of stakeholders with different values and objectives [29, 30]. This would justify the interest these methods have aroused in advanced European HTA agencies like the British NICE and the German IQWiG, regardless of some hasty and optimistic anticipation of MCDA applications reported in some articles but that never happened in practice-for example, for value-based pricing in the UK $[11,12,22,30]$, a scheme that has disappeared from the British political agenda. However, some of these authors also underlined that MCDA does not replace the decisionmakers' judgment [12], but rather identifies and processes the information needed to support the deliberative 
procedures [5]. In other terms, MCDA models are to be used as decision-making tools, but their application cannot replace human decisions, by definition [33].

The main intrinsic limit for health policy decisions on new technologies is the lack of vital information at the early stage of market approval. As a consequence, most HTA exercises on new drugs risk becoming mere forecasts that lead to speculation on future economic 'tradeoffs' [28], where insufficient clinical evidence is projected into the future on the basis of heterogeneous assumptions and estimates, adding pharmaceutical prices as an important source of variation. Although it is still hard to conclude whether HTA has succeeded 'because of' or 'despite' its multidisciplinary approach [25], its 'core' still remains EE, which is most useful and appropriate when supported by robust evidence of clinical efficacy [28]. The other main EE 'ingredients' suffer evident (though not insurmountable) limits. Measuring quality of life is a very hard and uncertain exercise, by definition [34], so any general scale to assess it necessarily stems from simplistic items that raise obvious skepticism [35]. Healthcare costs are dramatically affected by local features, differently from clinical efficacy, and can hardly be generalized [36]. Yet the two costing components (resource consumption and unit costs) are both hard to quantify if they are to be credible proxies of real costs. The former are rarely available from a single source and their collection often results in a piecemeal and patchy exercise [37]. The latter, ideally representing the 'opportunity cost' of the product/service considered, are only apparently easier to evaluate, starting from drug prices and hospital tariffs, which hardly stem from competitive markets [38].

According to the intrinsic limits of both MCDA and HTA methods, we wonder whether their mix can necessarily improve the credibility of pharmaceutical policy decision making. Although MCDA can support decision makers by stimulating reflection and discussion on decision 'drivers' [29], their apparent numerical precision might be misleading for stakeholders, giving the false impression that the final results are objective numbers, scientifically produced [39]. Moreover, these outputs may not necessarily change the attitude of some stakeholders in judging the final recommendations of regulatory authorities. For instance, patient groups are usually disappointed by negative decisions on drug reimbursement and the adoption of a MCDA is hardly likely to change their opinion in these circumstances [40]. Finally, it is even hard to predict whether the scoring and weighting of all key factors necessarily stimulates more debate among decision makers (the best expected MCDA result), rather than strengthening the role of technicians who manage the procedures [40].

\section{Policy Implications}

Although MCDA may have some merits in different fields and applications, we have some doubts about the utility of adding these methods on to HTA for pharmaceutical policy as a public priority. MCDA can hardly help tackle the toughest issue of European public agencies at present, that is flawed and uncertain clinical evidence $[40,41]$. The real 'crux of the matter' still remains the latest EMA tendency to fast-track drugs and thus limit companies' obligations mainly to less risky clinical trials, postponing the appraisal of relative efficacy until after marketing approval [42]. This strategy is fostered by the widespread 'political creed' that all new drugs must be available to patients as soon as possible [43], regardless of their therapeutic 'added value'. As a consequence, national $\mathrm{P} \& \mathrm{R}$ agencies increasingly suffer the lack of robust clinical evidence.

To conclude, if EMA does not radically change direction at the European level, we are afraid the national workload for $\mathrm{P} \& \mathrm{R}$ is likely to become hard to sustain for most EU Member States in the near future and sophisticated tools like MCDA run the risk of adding only one further complication for domestic pharmaceutical decisionmaking.

\section{Compliance with Ethical Standards}

Competing interests Livio Garattini and Anna Padula have no conflict of interest.

Funding No funding was received for this paper.

Ethical approval This work is not subject to ethical approval.

\section{References}

1. Greco S, Ehrgott M, Figueira JR. Multiple criteria decision analysis—state of the art surveys. New York: Springer; 2016.

2. Zopounidis C, Doumpos M. Multi-criteria decision aid in financial decision making: methodologies and literature review. J Multi-Criteria Decis Anal. 2002;11:167-86.

3. Belton V, Stewart T. Problem structuring and multiple criteria decision analysis. In: Greco S, Ehrgott M, Figuera JR, editors. Trends in multiple criteria decision analysis. London: Springer; 2010. p. 209-39.

4. Keeney RL, Raiffa H. Decision analysis with multiple conflicting objectives. New York: Wiley; 1976.

5. Thokala P, Devlin N, Marsh K, Baltussen R, Boysen M, Kalo Z, Longrenn T, Mussen F, Peacock S, Watkins J, Ijzerman M. Multiple criteria decision analysis for health care decision making - an introduction: report 1 of the ISPOR MCDA Emerging Good Practices Task Force. Value Health. 2016;19(1):1-13.

6. Celano G, Fichera S, Grasso V, et al. An evolutionary approach to multi-objective scheduling of mixed model assembly lines. Comput Ind Eng. 1999;37(1):69-73.

7. Haralambopoulos D, Polatidis H. Renewable energy projects: structuring a multi-criteria group decision-making framework. Renew Energy. 2003;28:961-73. 
8. Alvarez-Guerra M, Canis L, Voulvoulis N, et al. Prioritization of sediment management alternatives using stochastic multicriteria acceptability analysis. Sci Total Environ. 2010;408(20):4354-67.

9. Ligmann-Zielinska A, Jankowski P. Impact of proximity-adjusted preferences on rank-order stability in geographical multicriteria decision analysis. J Geogr Syst. 2012;14:167-87.

10. Diaby V, Campbell K, Goeree R. Multi-criteria decision analysis (MCDA) in health care: a bibliometric analysis. Oper Res Health Care. 2013;2:20-4.

11. Marsh K, Lanitis T, Neasham D, Orfanos P, Caro J. Assessing the value of healthcare interventions using multi-criteria decision analysis: a review of the literature. Pharmacoeconomics. 2014;32:1-21.

12. Devlin N, Sussex J. Incorporating multiple criteria in HTA. Methods and processes. London: Office of Health Economics; 2011.

13. Adunlin G, Diaby V, Xiao H. Application of multi-criteria decision analysis in health care: a systematic review and bibliometric analysis. Health Expect. 2015;18(6):1894-905.

14. European Medicine agency. Benefit-risk methodology project. 2009. http://www.ema.europa.eu/docs/en_GB/document_library/ Report/2011/07/WC500109477.pdf.

15. European Medicines Agency. Benefit-risk methodology project. Work package 4 report: benefit-risk tools and processes. 2015. http://www.ema.europa.eu/docs/en_GB/document_library/Report/ 2012/03/WC500123819.pdf.

16. Danner M, Hummel JM, Volz F, et al. Integrating patients' views into health technology assessment: analytic hierarchy process (AHP) as a method to elicit patient preferences. Int $\mathrm{J}$ Technol Assess Health Care. 2011;27:369-75.

17. IQWiG (Institute for Quality and Efficiency in Health Care). Analytic hierarchy process (AHP) - pilot project to elicit patient preferences in the indication "depression". 2015. https:// www.iqwig.de/download/Executive-summary-of-working-paper_ Analytic-Hierarchy-Process-pilot-project.pdf.

18. IQWiG (Institute for Quality and Efficiency in Health Care). Choice-based conjoint analysis—pilot project to identify, weight, and prioritize multiple attributes in the indication "hepatitis C". 2015. https://www.iqwig.de/download/GA10-03_Executivesummary-of-working-paper-1.1_Conjoint-Analysis.pdf.

19. National Institute for Health and Care Excellence. Developing NICE guidelines: the manual. Process and methods [PMG20]. 2014. https://www.nice.org.uk/process/pmg20/chapter/introductionand-overview.

20. Department for Communities and Local Government. Multi-criteria analysis: a manual. London: Department for Communities and Local Government; 2009.

21. Rao RV. Introduction to multiple attribute decision-making (MADM) methods. In: Rao RV, editor. Decision making in the manufacturing environment using graph theory and fuzzy multiple attribute decision making methods. London: Springer; 2007.

22. Mühlbacher AC, Kaczynski A. Making good decisions in healthcare with multi-criteria decision analysis: the use, current research and future development of MCDA. Appl Health Econ Health Policy. 2016;14:29-40.

23. Devlin N, Sussex J. Incorporating multiple criteria in HTA: methods and processes. London: Office of Health Economics; 2011.

24. Banta D. The development of health technology assessment. Health Policy. 2003;63(2):121-32.
25. Garattini L, Casadei G. Health technology assessment: for whom the bell tolls? Eur J Health Econ. 2008;9(4):311-2.

26. Garattini L, van de Vooren K, Curto A. Regional HTA in Italy: promising or confusing? Health Policy. 2012;108(2-3):203-6.

27. Duthie K, Bond K. Improving ethics analysis in health technology assessment. Int $\mathrm{J}$ Technol Assess Health Care. 2011;27(January):64-70.

28. Garattini L, Padula A. Dutch guidelines for economic evaluation: 'from good to better' in theory but further away from pharmaceuticals in practice? J R Soc Med. 2017;110(3):98-103.

29. Diaby V, Goeree R, Hoch J, Siebert U. Multi-criteria decision analysis for health technology assessment in Canada: insights from an expert panel discussion. Expert Rev Pharmacoecon Outcomes Res. 2015;15(1):13-9.

30. Goetghebeur M, Wagner M, Khoury H, Levitt R, Erickson L, Rindress D. Bridging HTA and efficient health care decision making with MCDA. Applying the EVIDEM framework to medicines appraisal. Med Decis Mak. 2011;32(2):376-88.

31. Angelis A, Kanavos P. Value-based assessment of new medical technologies: towards a robust methodological framework for the application of multiple criteria decision analysis in the context of health technology assessment. Pharmacoeconomics. 2016;34(5):435-46.

32. Marsh K, Caro JJ, Hamed A, Zaiser E. Amplifying each patient's voice: a systematic review of multi-criteria decision analyses involving patients. Appl Health Econ Health Policy. 2017;15(2):155-62.

33. Mussen F, Salek S, Walker S. A quantitative approach to benefitrisk assessment of medicines-part 1: the development of a new model using multi-criteria decision analysis. Pharmacoepidemiol Drug Saf. 2007;16:S2-15.

34. Kane RL. The futility of utility weighting. J Clin Epidemiol. 2008;61:1195-6.

35. Rawles J. Castigating QALYs. J Med Ethics. 1989;15(3):143-7.

36. Pagano E, Brunetti M, Tediosi F, Garattini L. Cost of diabetes: a methodological analysis of the literature. Pharmacoeconomics. 1999;15(6):583-95.

37. Garattini L, Ghislandi F, Da Costa MR. Cost-effectiveness modeling in multiple sclerosis: playing around with non-healthcare costs? Pharmacoeconomics. 2015;33(12):1241-4.

38. van de Vooren K, Curto A, Freemantle N, Garattini L. Marketaccess agreements for anti-cancer drugs. J R Soc Med. 2015;108(5):166-70.

39. Mussen F, Salek S, Walker S. A quantitative approach to benefitrisk assessment of medicines-part 1: the development of a new model using multi-criteria decision analysis; part 2: the practical application of a new model. Pharmacoepidemiol Drug Saf. 2007;16:S42-6.

40. Walker A. Challenges in using MCDA for reimbursement decisions on new medicines? Value Health. 2016;19:123-4.

41. Garattini L, Curto A, Padula A, Freemantle N. Real-world evidence in economic evaluations: really realistic? J R Soc Med. 2016;109(11):404-7.

42. Garattini L, Curto A. European Medicines Agency: leave the UK but remain the same? J R Soc Med. 2016;109(9):324-5.

43. Curto A, van de Vooren K, Garattini L. Market approval for drugs in the EU: time to change direction? Eur J Health Econ. 2016. doi:10.1007/s10198-016-0863-5. 